\title{
The sutureless valve redux: Innovation or hype?
}

\author{
Thomas G. Gleason, MD
}

\footnotetext{
From the Division of Cardiac Surgery, Department of Cardiothoracic Surgery, University of Pittsburgh School of Medicine, Pittsburgh, Pa.

Disclosures: Author has nothing to disclose with regard to commercial support.

Received for publication Oct 17, 2015; accepted for publication Oct 19, 2015; available ahead of print Nov 18 , 2015.

Address for reprints: Thomas G. Gleason, MD, Division of Cardiac Surgery, Department of Cardiothoracic Surgery, University of Pittsburgh School of Medicine, 5200 Centre Ave, Suite 715, Pittsburgh, PA 15232 (E-mail: gleasontg@upmc.edu).

J Thorac Cardiovasc Surg 2016;151:743-4

$0022-5223 / \$ 36.00$

Copyright (c) 2016 by The American Association for Thoracic Surgery

http://dx.doi.org/10.1016/j.jtcvs.2015.10.057
}

The fervor for a "sutureless" valve is not new. The late George J. Magovern, along with Harry Cromie, designed a ball valve with annular fixation pins emanating from the annular ring of a caged-ball valve more than 50 years ago in Pittsburgh. Their valve was first reported after one was implanted in a 43-year old woman with aortic regurgitation on April 13, 1962. ${ }^{1,2}$ The total bypass time for that case was 28 minutes. Astonishingly, one of these early valves, implanted in a 23-year old man that same year, functioned without complication for 42 subsequent years-the longest functioning prosthetic valve ever documented." Magovern's aim at the time was "to simplify the method of fixation, lessen bypass time, and reduce thrombus formation. . . with rapid mechanical fixation," ${ }^{1}$ because the value of reducing cardiopulmonary bypass (CPB) time was absolutely evident in that era, when complication rates were high.

Since then, the safety of CPB and our capabilities of performing even extraordinarily complex cardiac reconstructions have been subsequently realized. Despite these advances, there is an ever-pressing desire, both by surgeons and patients, to fix hearts less invasively, in less time, with less difficulty. To this end, there has been a recent explosion of technology in automating structural heart solutions. This latest resurgence of the "sutureless" valve concept is but one example of this revolution. De Varennes and colleagues present in this month's issue of the Journal a single-institutional series of 63 cases of their use of the Medtronic 3f Enable Aortic Bioprosthetic sutureless valve (Minneapolis, Minn) for the treatment of severe aortic stenosis with good results. This valve was the first commercially available sutureless bioprosthetic valve, having obtained Conformité Européenne Mark in December 2009. De Varennes and colleagues report its use in patients with a mean Society of Thoracic Surgeons Predicted Risk of Mortality score of $8.1 \%$ and a range of $0.9 \%$ to $41.3 \%$. Their criterion for its use in this series was either a Society of Thoracic Surgeons Predicted Risk of Mortality score of $5 \%$ or greater (moderate risk) or the presence of "comorbid conditions where a shorter CPB

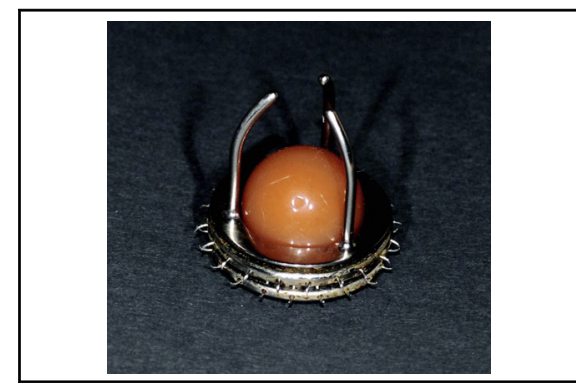

Sutureless valve redux: The Magovern-Cromie valve first implanted in 1962.

\section{Central Message}

Durability, direct costs, and a marginal clinical value may limit enthusiasm for sutureless bioprosthetic valves.

See Article page 735 .

See Editorial page 610

time or minimally invasive approach would potentially reduce perioperative complications"- - the presumption being that the sutureless valve portends these benefits.

The device was implanted with technical success in all but 3 cases, each of which required removal and replacement, 2 with a larger Enable valve and one with a conventionally sewn stented bioprosthesis. The operative mortality was commensurate with a moderate risk cohort at $3.2 \%$, and the pacemaker and paravalvular leak rates were acceptably low at $3.2 \%$ and $6 \%$, respectively. The average peak and mean gradients at completion were reasonable at 19 and $10 \mathrm{~mm} \mathrm{Hg}$, respectively. Mean follow-up, however, was only 10.7 months. The investigators tout an advantage of implanting the Enable valve is that it can be done through a very high aortotomy $(5-6 \mathrm{~cm})$ relative to the sinotubular junction, potentially pertinent to cases of severe proximal aortic root calcifications or the presence of indwelling coronary bypass grafts on the proximal aorta. Despite this apparent utility, they replaced the ascending aorta in 3 cases. A potential concern of the device is that its outer diameter at the annular fixation cuff is $6 \mathrm{~mm}$ larger than the $3 \mathrm{f}$ valve diameter that is within the nitinol frame; the valve size (diameter) chosen for a given individual thus must be 2 to $4 \mathrm{~mm}$ smaller than the native annular size measured to allow for adequate radial force (and thus fixation) from the prosthesis to the annulus. This may explain why postoperative mean gradients were not in the low single digits. 
The primary enthusiasm for the sutureless valve concept is that it will facilitate shorter CPB times or minimally invasive approaches (eg, ministernotomy or mini-anterior thoracotomy) for aortic valve replacement (AVR). In this current series, as aptly pointed out by De Varennes and colleagues, the mean crossclamp time for isolated AVR was $44 \pm 14$ minutes and for combined procedures (mostly AVR with coronary artery bypass grafting) was $77 \pm 31$ minutes, times that are not appreciably different from the recently published larger series of conventional AVRs, in which Thalji and colleagues ${ }^{4}$ showed in a series of more than 1300 cases of AVR or AVR with coronary artery bypass grafting that crossclamp times were $47 \pm 17$ minutes and $79 \pm 27$ minutes, respectively. Studies directly comparing sutureless AVR through a ministernotomy to conventional AVR through a sternotomy or simply ministernotomy AVR with sternotomy AVR have failed to demonstrate an appreciable (ie, clinically relevant) difference in CPB time that also correlates with significant differences in outcome quality measures. ${ }^{5-8}$ Thus, given the safety and efficacy of modern $\mathrm{CPB}$ and myocardial protection strategies, the question is whether 5 to 20 minutes in crossclamp time savings is really going to translate into better outcomes, particularly over the long term.

Market forces, driven by hospital and surgeon competition, industry giants, and consumers, are very much at play in this arena. The attraction, particularly to consumers, of the ministernotomy (and thus things that might facilitate it) is both cosmetic and the perception that it is less invasive. These attractions notwithstanding, it has been difficult to demonstrate that ministernotomy or minithoracotomy yields better primary outcomes (eg, mortality, stroke, or major complication rates) or even quality-of-life indicators, particularly when measured beyond the perioperative period. Irrespective of incision size, the "elephant in the room" with sutureless aortic valve technologies specifically is their financial cost and their unknown durability relative to conventionally sewn aortic bioprostheses. As health care costs continue to rise and large populations of patients are either underinsured or see rationed care, trimming direct costs may be a more relevant concern for the modern era than trimming crossclamp time. The rationale that costly valve technologies can be justified by their ability to reduce hospital stay and decrease morbidity has not yet been realized, particularly when studied in moderate-risk aortic stenosis populations ${ }^{9}$ such as those in the study of De Varennes and colleagues. Moving forward, there is little doubt that the current value of the sutureless valve will be dictated by the market, but in the end it will be measured by the long-term outcomes of the "minimally invaded."

\section{References}

1. Magovern GJ, Kent EM, Cromie HW. Sutureless artificial heart valves. Circulation. 1963:27:2784-8.

2. Magovern GJ, Cromie HW. Sutureless prosthetic heart valves. J Thorac Cardiovasc Surg. 1963;46:726-36.

3. Zlotnick AY, Shiran A, Lewis BS, Aravot D. Images in cardiovascular medicine. A perfectly functioning Magovern-Cromie sutureless prosthetic aortic valve 42 years after implantation. Circulation. 2008;117:e1-2.

4. Thalji NM, Suri RM, Daly RC, Greason KL, Dearani JA, Stulak JM, et al. The prognostic impact of concomitant coronary artery bypass grafting during aortic valve surgery: implications for revascularization in the transcatheter era. $J$ Thorac Cardiovasc Surg. 2015;149:451-60.

5. Borger MA, Moustafine V, Conradi L, Knosalla C, Richter M, Merk DR, et al. A randomized multicenter trial of minimally invasive rapid deployment versus conventional full sternotomy aortic valve replacement. Ann Thorac Surg. 2015; 99:17-25.

6. Lehmann S, Merk DR, Etz CD, Seeburger J, Schroeter T, Oberbach A, et al. Minimally invasive aortic valve replacement: the Leipzig experience. Ann Cardiothorac Surg. 2015;4:49-56.

7. D’Onofrio A, Rizzoli G, Messina A, Alfieri O, Lorusso R, Salizzoni S, et al. Conventional surgery, sutureless valves, and transapical aortic valve replacement: what is the best option for patients with aortic valve stenosis? A multicenter, propensity-matched analysis. J Thorac Cardiovasc Surg. 2013;146:1065-70; discussion 1070-1.

8. Furukawa N, Kuss O, Aboud A, Schönbrodt M, Renner A, Hakim Meibodi K, et al. Ministernotomy versus conventional sternotomy for aortic valve replacement: matched propensity score analysis of 808 patients. Eur J Cardiothorac Surg. 2014;46:221-6; discussion 226-7.

9. Osnabrugge RL, Head SJ, Genders TS, Van Mieghem NM, De Jaegere PP, van der Boon RM, et al. Costs of transcatheter versus surgical aortic valve replacement in intermediate-risk patients. Ann Thorac Surg. 2012;94:1954-60. 